\title{
Inhibition Performance Study of Vanadate on AA2024-T3 at High Temperature by SEM, FIB, Raman and XPS
}

\author{
Jichao Li, Belinda Hurley, ${ }^{*}$ and Rudolph Buchheit**,z \\ Fontana Corrosion Center, Department of Materials Science and Engineering, The Ohio State University, \\ Columbus, Ohio 43210, USA
}

\begin{abstract}
The inhibition of AA2024-T3 by vanadate at temperatures ranging from $10^{\circ}$ to $80^{\circ} \mathrm{C}$ was studied using various characterization techniques. SEM showed that in the presence of vanadate, no corrosion was observed on any intermetallic particles, including the reactive $\mathrm{Al}_{2} \mathrm{CuMg}$ (S phase) at temperatures up to $50^{\circ} \mathrm{C}$. Although trenching occurred around the $\mathrm{S}$ phase particles when solution temperature increased to $70^{\circ} \mathrm{C}$ and above, $\mathrm{S}$ phase was protected by vanadate-bearing film. Raman spectroscopy showed a peak indicating polymeric vanadate, which increased in intensity with increasing temperature with the highest intensity at $80^{\circ} \mathrm{C}$. The high vanadium concentration at $80^{\circ} \mathrm{C}$ was attributed to fast reduction reaction kinetics of vanadate by $\mathrm{Al}$ or $\mathrm{Mg}$. This reduction reaction is confirmed by XPS, and the reduced forms of vanadium appeared to promote vanadate $\left(\mathrm{V}^{5+}\right)$ polymerization leading to the formation of vanadate films. Additionally, elevated temperatures appeared to increase vanadate polymerization kinetics. This reductive adsorbed vanadate film also enabled the samples treated in vanadate at higher temperature to have residual inhibition in $\mathrm{NaCl}$ without inhibitors. The reduced forms of vanadium were found to be easily oxidized under ambient aerated solution conditions. Exposure of treated samples in air further increased the corrosion resistance.

(C) The Author(s) 2015. Published by ECS. This is an open access article distributed under the terms of the Creative Commons Attribution 4.0 License (CC BY, http://creativecommons.org/licenses/by/4.0/), which permits unrestricted reuse of the work in any medium, provided the original work is properly cited. [DOI: 10.1149/2.0371506jes] All rights reserved.
\end{abstract}

Manuscript submitted January 12, 2015; revised manuscript received February 19, 2015. Published March 2, 2015.

AA2024-T3 (Al-4.4Cu-2.5Mg-0.6Mn) is a high strength $\mathrm{Al}$ alloy that is susceptible to many forms of localized corrosion due to its heterogeneous microstructure. ${ }^{1,2}$ Localized corrosion is focused at secondary phase intermetallic compounds (IMCs). ${ }^{3,4}$ Two common IMCs of interest in AA2024 are S-phase $\left(\mathrm{Al}_{2} \mathrm{CuMg}\right)$ and $\mathrm{AlCuFeMn}(\mathrm{Si})$ particles. These two IMC types account for the majority of particles found in AA2024, both in number and surface area. ${ }^{4,5} \mathrm{AlCuFeMn}(\mathrm{Si})$ particles generally act as cathodes to the matrix, and corrosion occurs as trenching around the particles under corrosive conditions. ${ }^{3,6-10}$ S-phase particles are initially active and dissolve by dealloying. ${ }^{4}$ However, upon the dissolution of $\mathrm{Mg}$ and $\mathrm{Al}$ from these particles, they become $\mathrm{Cu}$-rich and thereafter act as a local cathode., $, 6,11-13$

In view of recent advances in understanding the chemistry of vanadate, it has become an intriguing inhibitor to the research community. ${ }^{14-20}$ Vanadate has proven to be a promising candidate to replace toxic chromate as a corrosion inhibitor. In particular, vanadate has shown good inhibition on aluminum alloys in the form of soluble vanadate, ${ }^{17-26}$ vanadate-based coatings, ${ }^{27-29}$ and ion exchange compounds pigment for primers. ${ }^{30}$ Iannuzzi et al. used polarization and split cell experiments to show that vanadate acted as a cathodic inhibitor on AA2024 by suppressing the oxygen reduction reaction (ORR) by a physically adsorbed vanadate monolayer. ${ }^{23,24}$ The inhibition of vanadate on AA2024-T3 was also reported by Ralston et al. while studying corrosion inhibition imparted by vanadate on IMCs found in AA2024 and AA7075-T6. ${ }^{25,31}$

The effect of temperature on protection provided by corrosion inhibitors has been the subject of many studies. For example, the rate of film formation of chromate conversion coatings on metal surfaces is accelerated when the solution bath is heated. ${ }^{32}$ Slight improvement in corrosion resistance can be obtained when a chromate conversion coating is applied to Ni-P alloys at elevated temperatures. ${ }^{33}$ Lin et al. noted a temperature-dependent reduced incubation time for the formation of a stannate conversion coating on AZ61 Mg alloys. ${ }^{15}$ Previous work examining vanadate as a corrosion inhibitor on aluminum alloys was undertaken under ambient temperatures. ${ }^{17,18,20-22,24,25,27,28,31}$ Being a thermally activated process, the kinetics of corrosion reactions are expected to be accelerated at elevated temperatures. ${ }^{34,35}$ In particular, temperature will affect the galvanic coupling between active and cathodic sites on the alloy's surface. This work examines the temperature-dependence of vanadate corrosion inhibition of AA2024-
T3. Characterization of vanadate films formed at various temperatures is compared and contrasted with current understanding of vanadate inhibition and knowledge of previously successful corrosion inhibition systems such as chromate to develop insight into the value of vanadate as an inhibitor at elevated temperatures.

\section{Experimental}

Materials and sample preparation.- Reagent grade $\mathrm{NaVO}_{3}$ (96\%) was used for all experiments. The substrate was AA2024-T3 sheet, 0.0635 inch $(1.6 \mathrm{~mm})$ thick. All solutions were prepared with deionized ((DI)) water with a minimum resistivity of $18.2 \mathrm{M} \Omega^{*} \mathrm{~cm}$. All aqueous $\mathrm{NaVO}_{3}$ solutions were $4.0 \mathrm{mM}$; the $\mathrm{pH}$ of 7.7 was adjusted to 9.2 with the drop-wise addition of concentrated $\mathrm{NaOH}(99.9 \%)$, and was used for experiments immediately. A pH of 9.2 was deliberately chosen to produce solutions that likely contain tetrahedral vanadate species. ${ }^{25}$ All samples were (1) cut to $\sim 15 \mathrm{~mm} \times 15 \mathrm{~mm},(2)$ abraded with successive grades of SiC paper to 1200 grit using ethanol (200 proof) as a lubricant, (3) polished in $1 \mu \mathrm{m}$ diamond paste on polishing cloth and (4) ultrasonically cleaned with ethanol to remove organic residue. Immersion at the desired temperature (described below) was carried out immediately after polishing.

Exposure tests at a various temperatures were accomplished with the use of a $400 \mathrm{~mL}$ jacketed beaker equipped with two hose connections to permit circulation of temperature-controlled water between jackets. The immersion procedure consisted of the following steps: (1) $\sim 100 \mathrm{~mL}$ of room temperature, $\mathrm{pH}$ (9.2) adjusted, aqueous $4.0 \mathrm{mM} \mathrm{NaVO}$ was placed in the jacketed beaker and was preheated or pre-cooled to $10,30,50,70$, or $80^{\circ} \mathrm{C}$ with circulating water from the temperature bath for $\sim 40$ minutes; (2) a polished sample was placed horizontally on the bottom of the jacketed beaker in the heated/cooled electrolyte; (3) temperature-controlled water continued to flow through the jacketed walls for an additional 60 minutes; (4) after 60 minutes at the desired temperature, each sample was immediately rinsed in DI water and ethanol and air dried. Exposure of control samples followed the same steps, except that DI water was substituted in place of $4.0 \mathrm{mM} \mathrm{NaVO}_{3}$. $\mathrm{pH}$ measurements with temperature compensation indicated that $\mathrm{pH}$ varied by $<0.3 \mathrm{pH}$ units for the $4.0 \mathrm{mM} \mathrm{NaVO}$ solution over a temperature range of $30-80^{\circ} \mathrm{C}$. Therefore, speciation changes attributable to $\mathrm{pH}$ changes were essentially nonexistent.

Instrumental.- Nuclear magnetic resonance (NMR) spectra $\left({ }^{51} \mathrm{~V}\right)$ of $4.0 \mathrm{mM}$ vanadate with a $\mathrm{pH}$ of 9.2 at 30,50 , and $70^{\circ} \mathrm{C}$ were collected

\footnotetext{
*Electrochemical Society Active Member.

**Electrochemical Society Fellow.

${ }^{\mathrm{z}}$ E-mail: buchheit.8@osu.edu
} 
Table I. Binding energy constraints used for Gaussian-Lorentzian fitting of XPS peaks.

\begin{tabular}{cllllll} 
Species & $\mathrm{V} 2 \mathrm{p}_{3 / 2}\left(\mathrm{~V}^{5+}\right)$ & $\mathrm{V} \mathrm{2} \mathrm{p}_{3 / 2}\left(\mathrm{~V}^{4+}\right)$ & $\mathrm{V} \mathrm{2} 2 \mathrm{p}_{1 / 2}\left(\mathrm{~V}^{5+}\right)$ & $\mathrm{V} 2 \mathrm{p}_{1 / 2}\left(\mathrm{~V}^{4+}\right)$ & $\mathrm{O} 1 \mathrm{~s}\left(\mathrm{~V}_{\mathrm{x}} \mathrm{O}_{\mathrm{y}}\right)$ & $\mathrm{O} 1 \mathrm{~s}\left(\mathrm{Al}_{2} \mathrm{O}_{3}\right)$ \\
\hline Fit Constraint $(\mathrm{eV})$ & $517.2 \pm 0.1$ & $515.8 \pm 0.2$ & $524.5 \pm 0.1$ & $523.2 \pm 0.2$ & $530.0 \pm 0.5$ & $532.0 \pm 0.5$
\end{tabular}

using a $500 \mathrm{MHz}$ superconducting magnet to identify temperature dependent vanadate species changes. A $5 \mathrm{~mm}$ detection probe with a $90^{\circ}$ pulse duration of $55 \mu$ s was used. Spectra were collected with an accumulation of 1024 transients. The spectra window was $66006 \mathrm{~Hz}$ with an acquisition time of $0.03 \mathrm{~s}$ and relaxation delay of $0.02 \mathrm{~s}$. The ${ }^{51} \mathrm{~V}$ chemical shift was referenced to external pure liquid $\mathrm{VOCl}_{3}$ $\left(\delta^{51} \mathrm{~V}=0\right.$ parts per million (ppm)).

Raman spectra were acquired with $514 \mathrm{~nm}$ excitation on a Raman microprobe system with a $50 \mathrm{X}$ objective $(\mathrm{NA}=0.75)$, power of $\sim 12 \mathrm{~mW}$ at sample, and an integration time of $10 \mathrm{~s}$. Raman spectra of the matrix were acquired once for each temperature exposure condition, except $50^{\circ} \mathrm{C}$. Raman spectra of samples exposed at $50^{\circ} \mathrm{C}$ were acquired a minimum of 3 times from different samples which had each been exposed at $50^{\circ} \mathrm{C}$ on different days. Raman spectra of unidentified IMCs exposed at various temperatures were acquired a minimum of 2 times.

X-ray photoelectron spectroscopy (XPS) spectra were acquired with a monochromatic $120 \mathrm{~W} \mathrm{Al}$ source. Survey scans (range of $5 \mathrm{eV}$ to $1400 \mathrm{eV}$ ) were performed with a pass energy of $80 \mathrm{eV}$; O 1s and $\mathrm{V} 2 \mathrm{p}$ spectra were acquired simultaneously (range of $510 \mathrm{eV}$ to $540 \mathrm{eV}$ ) with pass energy of $20 \mathrm{eV}$. Samples were transferred from controlled environments to the XPS chamber under ambient conditions as quickly as possible. All spectra were calibrated with the 284.6 eV C 1s signals. Mixed Lorentzian-Gaussian (30\% Lorentzian) fitting was performed on the $\mathrm{O} 1 \mathrm{~s}$ and the $\mathrm{V} 2 \mathrm{p}$ peaks. The constraints used for the fitting of the V $2 p$ peaks (Table I) were established based on literature values for $\mathrm{V}_{2} \mathrm{O}_{5}$ and $\mathrm{VO}_{2},{ }^{36}$ while the constraints used for fitting the $\mathrm{O} 1 \mathrm{~s}$ peaks (Table I) were based on literature values for vanadium oxides ${ }^{36}$ and aluminum oxide. ${ }^{37}$ For V 2 p signal fitting, the area ratio of $\mathrm{V} 2 \mathrm{p}_{3 / 2}$ to $\mathrm{V} 2 \mathrm{p}_{1 / 2}$ was set as $2: 1$. For each sample, the XPS spectra were collected at two different positions.

Energy dispersive spectroscopy (EDS) analysis was performed on a Sirion scanning electron microscope (SEM) with a working distance of $10 \mathrm{~mm}$. Focused Ion Beam (FIB) analysis was performed with a $30 \mathrm{keV} \mathrm{Ga}$ ion beam.

Electrochemical measurements.-All Electrochemical Impedance Spectroscopy (EIS) measurements were carried out in a $0.1 \mathrm{M} \mathrm{NaCl}$ solution at room temperature using a Gamry Reference 600 employed with a standard 3-electrode setup. A saturated calomel electrode (SCE) served as the reference electrode and Pt mesh as the counter electrode. Samples were immersed for 10 minutes at OCP beore commencement of EIS measurements. EIS spectra were collected from $10 \mathrm{kHz}$ to $10 \mathrm{mHz}$ using a $10 \mathrm{mV}$ amplitude sinusoidal voltage perturbation superimposed on a direct current potential set as the open circuit potential. Spectra

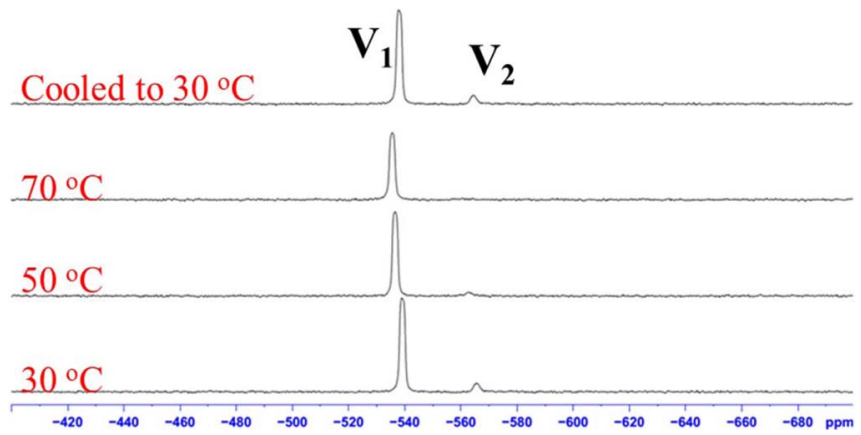

Figure 1. NMR spectra of $4 \mathrm{mM} \mathrm{NaVO} 3$ with a pH of 9.2 as a function of temperature. were collected at a rate of 7 points per decade, and each experiment was replicated 2 times. The EIS spectra were fitted using a simplified Randles circuit, which consisted of an electrolyte resistance in series with a parallel combination of a constant phase element and a polarization resistance $\left(R_{p}\right)$.

\section{Results}

NMR analysis. - To determine vanadate species present in the $4.0 \mathrm{mM}$ vanadate solution at various temperatures, in situ temperaturecontrolled NMR spectra were acquired of the $\mathrm{pH}$-adjusted solution at 30,50 , and $70^{\circ} \mathrm{C}$ and are shown in Fig. 1 . At $30^{\circ} \mathrm{C}$, two chemical shifts were observed at -539.6 and $-565.49 \mathrm{ppm}$ and were determined to be $\mathrm{HVO}_{4}{ }^{2-}\left(\mathrm{V}_{1}\right)$ and $\mathrm{HV}_{2} \mathrm{O}_{7}{ }^{3-}\left(\mathrm{V}_{2}\right)$, respectively. ${ }^{38}$ The fraction of $\mathrm{V}_{2}$ was very small at $30^{\circ} \mathrm{C}(\sim 9 \%)$ and appeared to decrease with increasing temperature, with no visible peak in the spectrum acquired at $70^{\circ} \mathrm{C}$. However, when the sample was re-cooled to $30^{\circ} \mathrm{C}$ from $70^{\circ} \mathrm{C}$, the peak attributable to $\mathrm{V}_{2}$ reappeared and its fraction was the same as that determined in the original spectrum acquired at $30^{\circ} \mathrm{C}$. The chemical shift attributed to $\mathrm{V}_{1}$ moved about $2.3 \mathrm{ppm}$ lower as the temperature increased to $70^{\circ} \mathrm{C}$, but it also returned to its original position when the sample was returned to $30^{\circ} \mathrm{C}$.

Raman analysis.- Raman surface analysis was performed on the matrix and on unidentified IMCs of samples exposed for $60 \mathrm{~min}$ in $4.0 \mathrm{mM} \mathrm{NaVO}_{3}$ at 10, 30, 50, 70 and $80^{\circ} \mathrm{C}$. Fig. 2 and Fig. 3 show

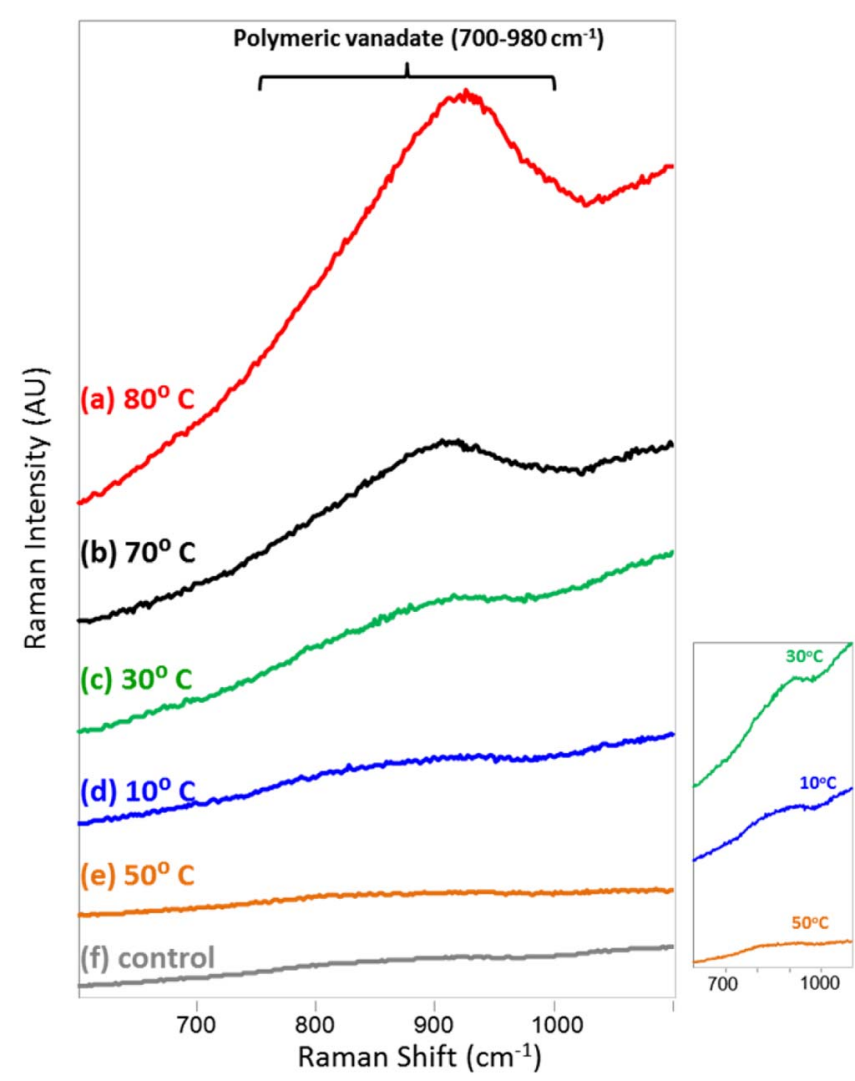

Figure 2. Overlaid Raman spectra of matrix of 2024 treated in aqueous $\mathrm{NaVO}_{3}$ at: (a) $80^{\circ} \mathrm{C}$, (b) $70^{\circ} \mathrm{C}$, (c) $30^{\circ} \mathrm{C}$, (d) $10^{\circ} \mathrm{C}$, (e) $50^{\circ} \mathrm{C}$ (f) control, untreated matrix. (Magnified view of 10,30 , and $50^{\circ} \mathrm{C}$ spectra.) 


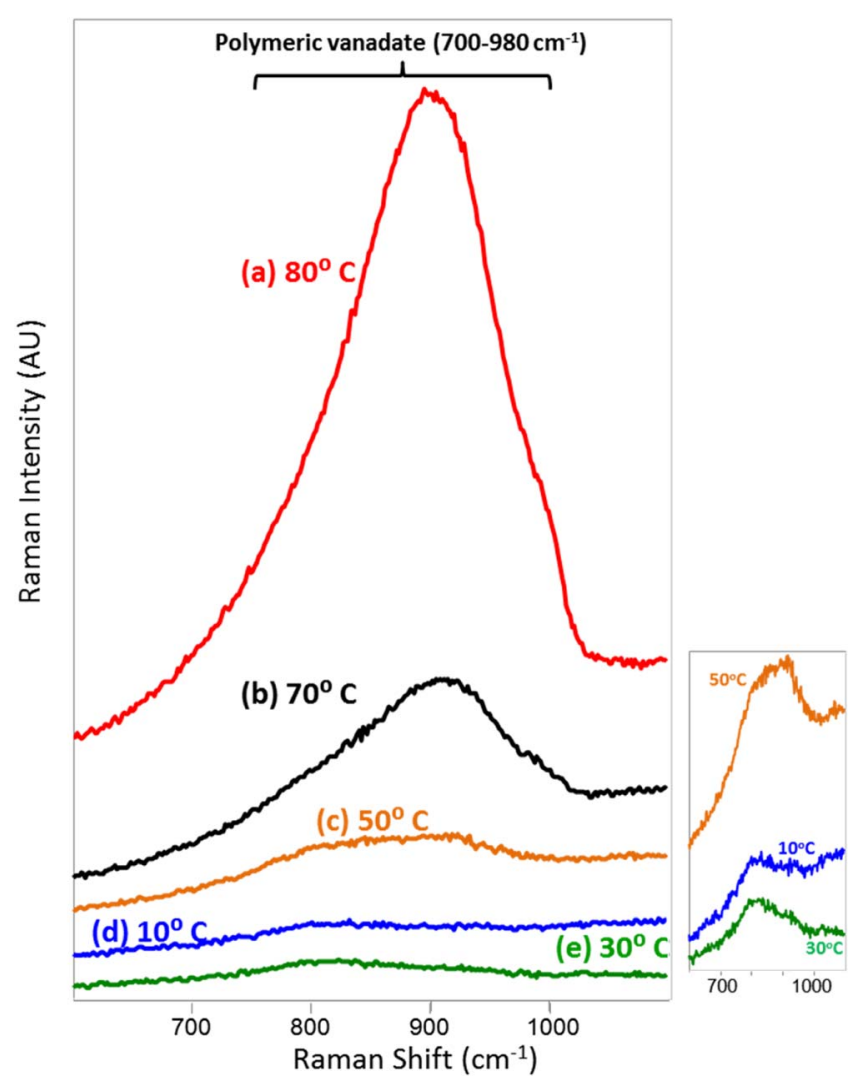

Figure 3. Overlaid Raman spectra of unidentified IMCs on 2024 treated in aqueous $\mathrm{NaVO}_{3}$ at: (a) $80^{\circ} \mathrm{C}$, (b) $70^{\circ} \mathrm{C}$, (c) $50^{\circ} \mathrm{C}$, (d) $10^{\circ} \mathrm{C}$, (e) $30^{\circ} \mathrm{C}$. (Magnified view of 10,30 , and $50^{\circ} \mathrm{C}$ spectra).

spectra of the matrix and IMCs after exposure at the various temperatures. The wide band between 700 and $980 \mathrm{~cm}^{-1}$ dominating the spectra of samples exposed at 70 and $80^{\circ} \mathrm{C}$ was attributed to polymerized vanadate. ${ }^{19}$ In general, the results showed an increase in polymerized vanadate on the matrix surface with increasing temperature, with little, if any evidence of the presence of polymerized vanadate on samples immersed at 10,30 and $50^{\circ} \mathrm{C}$. It should be noted that control spectra of untreated AA2024 revealed that the untreated matrix also produces a very weak band in the range from 725 to $1000 \mathrm{~cm}^{-1}$. Fortunately, in addition to being exceptionally weak, the band produced by the untreated matrix (most likely due to $\mathrm{Al}_{2} \mathrm{O}_{3}$ ) has a different shape than that produced by polymerized vanadate, making it possible to distinguish between the two overlapping bands. Analysis of samples exposed at $50^{\circ} \mathrm{C}$ repeatedly produced spectra weaker than those from samples exposed at 10 and $30^{\circ} \mathrm{C}$. In addition to the spectra of the exposed matrix shown in Fig. 2, spectra were also acquired of IMCs on the same samples. The specific identity of the IMCs analyzed could not be obtained with the Raman microprobe, but it is noteworthy that a similar trend was present on IMCs. The quantity of polymerized vanadate increased with increasing temperature. The $700-980 \mathrm{~cm}^{-1}$ band arising from spectra of exposed IMCs indicated the presence of polymerized vanadate at all temperatures (Fig. 3). For samples exposed at 10,30 and $50^{\circ} \mathrm{C}$, the intensities were slightly stronger than the respective spectra of the matrix. Spectra of IMCs exposed at 70 and $80^{\circ} \mathrm{C}$ displayed exceptionally strong bands in the $700-980 \mathrm{~cm}^{-1}$ range.

XPS analysis.-XPS analysis was undertaken on two types of samples exposed to $4.0 \mathrm{mM} \mathrm{NaVO}$ at $80^{\circ} \mathrm{C}$ for $60 \mathrm{~min}$. After exposure, rinsing and air drying, samples were placed in either an argon gas environment or a desiccator. These two samples produced distinctly different spectra as can be seen in Fig. 4A. The sample kept in dry air

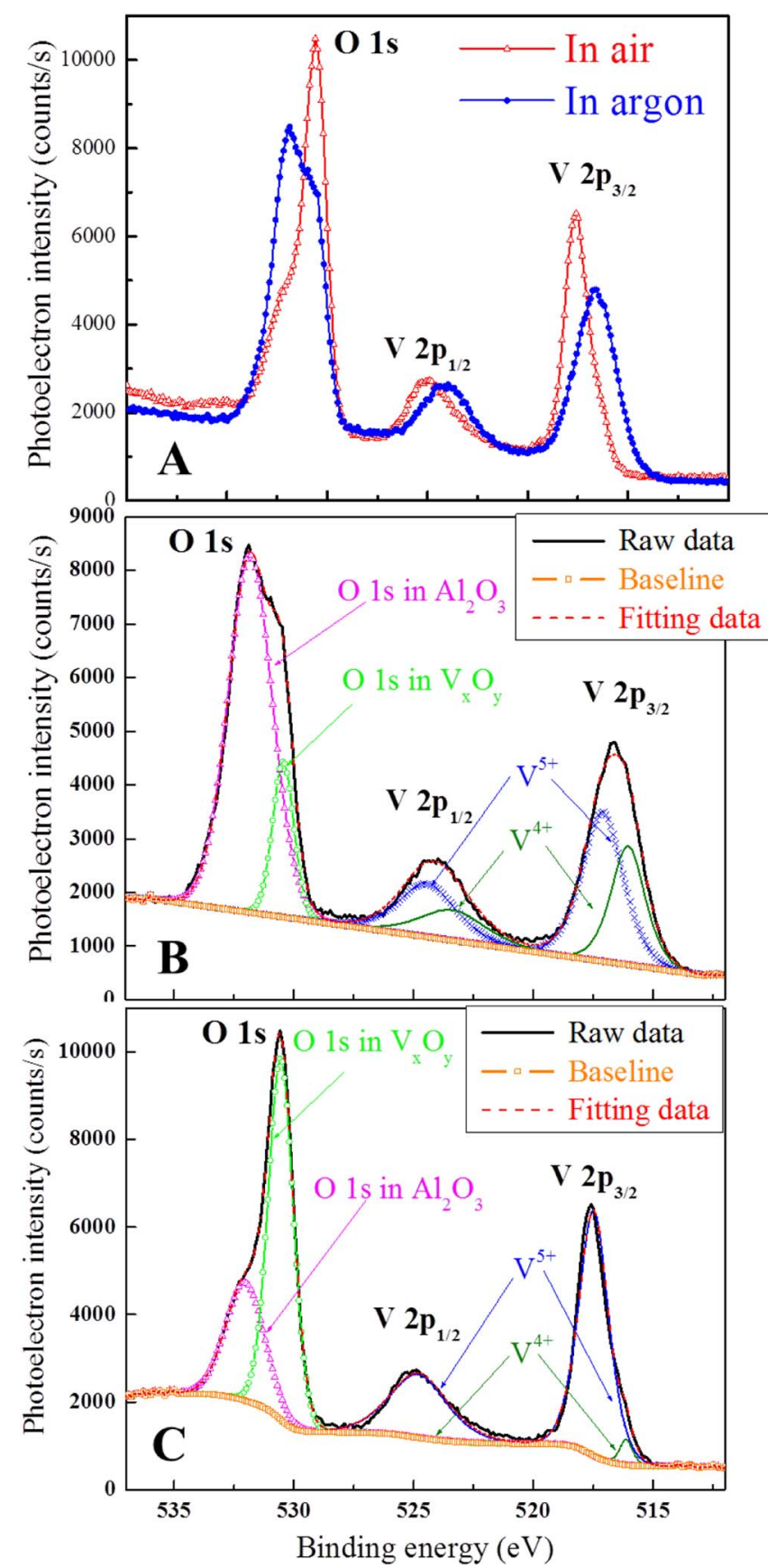

Figure 4. XPS spectra and fitting data of two samples after exposure in $4.0 \mathrm{mM} \mathrm{NaVO} 3$ at $80^{\circ} \mathrm{C}$ : (A) original XPS data; (B) fitting data for sample stored in argon environment; (C) fitting data for sample stored in dried air. Raw data, black; Baseline, gold; Fitting, red.

(desiccated) produced a sharp $\mathrm{O} 1 \mathrm{~s}$ peak with maximum intensity at $530.4 \mathrm{eV}$ and a shoulder observed at a slightly higher binding energy, a somewhat broad $V 2 p_{1 / 2}$ peak with maximum intensity at 525.1 and a sharp V $2 p_{3 / 2}$ at $517.4 \mathrm{eV}$. The sample kept in argon produced a more complex spectrum, with broader peaks and more shoulders. In general, the sample in argon produced an $\mathrm{O} 1 \mathrm{~s}$ peak with its maximum value at $532.0 \mathrm{eV}$ and a shoulder at lower binding energy, a broad $\mathrm{V} 2 \mathrm{p}_{1 / 2}$ peak with maximum intensity at $524.0 \mathrm{eV}$, and a somewhat broad $\mathrm{V} 2 \mathrm{p}_{3 / 2}$ with a maximum at $516.8 \mathrm{eV}$. Using the constraints noted in the Experimental section, a mixed Gaussian-Lorentzian fit provided the fitted peaks noted in Table II and shown in Fig. 4B and Fig. 4C. 
Table II. Values of Gaussian-Lorentzian fit (binding energy) for samples exposed at $80^{\circ} \mathrm{C}$ and subsequently stored in either an argon environment or a dry air environment. Fit is shown in Fig. 4B and $4 \mathrm{C}$.

\begin{tabular}{cccccc} 
& \multicolumn{2}{c}{ Argon Environment } & & \multicolumn{2}{c}{ Air Environment } \\
\cline { 2 - 3 } \cline { 6 - 6 } & $\mathrm{Al}_{2} \mathrm{O}_{3} \mathrm{fit}$ & $\mathrm{V}_{\mathrm{x}} \mathrm{O}_{\mathrm{y}} \mathrm{fit}$ & & $\mathrm{Al}_{2} \mathrm{O}_{3} \mathrm{fit}$ & $\mathrm{V}_{\mathrm{x}} \mathrm{O}_{\mathrm{y}} \mathrm{fit}$ \\
\hline $\mathrm{O} \mathrm{O} 1 \mathrm{~s}$ & $531.9 \mathrm{Ev}$ & $530.5 \mathrm{eV}$ & & $532.1 \mathrm{eV}$ & $530.6 \mathrm{eV}$ \\
& $\mathrm{V}_{2} \mathrm{O}_{5} \mathrm{fit}^{*}$ & $\mathrm{VO}_{2} \mathrm{fit}^{*}$ & & $\mathrm{~V}_{2} \mathrm{O}_{5} \mathrm{fit}^{*}$ & $\mathrm{VO}_{2} \mathrm{fit}^{*}$ \\
\hline $\mathrm{V} 2 \mathrm{p} 1 / 2$ & $524.5 \mathrm{eV}$ & $523.6 \mathrm{eV}$ & & $524.9 \mathrm{eV}$ & $523.5 \mathrm{eV}$ \\
$\mathrm{V} 2 \mathrm{p} \mathrm{3/2}$ & $517.2 \mathrm{eV}$ & $516.1 \mathrm{eV}$ & & $517.5 \mathrm{eV}$ & $516.2 \mathrm{eV}$
\end{tabular}

${ }^{*} \mathrm{~V}_{2} \mathrm{O}_{5}$ and $\mathrm{VO}_{2}$ literature values were used to establish the presence of $\mathrm{V}^{5+}$ and $\mathrm{V}^{4+}$, respectively. ${ }^{36}$

SEM/EDS analysis.- Fig. 5 shows SEM images of samples immersed in DI water at 50 and $70^{\circ} \mathrm{C}$ for $60 \mathrm{~min}$. Fig. 5A and 5B present full surface views of the matrix and surrounding IMCs, while Fig. 5C and 5D present magnified views of IMCs. As can be readily seen in Fig. 5B, considerable localized corrosion and trenching around IMCs was present after $60 \mathrm{~min}$ at $70^{\circ} \mathrm{C}$. The magnified image in Fig. 5D displays the trenching morphology observed after exposure at $70^{\circ} \mathrm{C}$ at an $\mathrm{AlCuFeMn}(\mathrm{Si})$ particle. The color contrast displayed in the SEM images of the $\mathrm{AlCuFeMn}(\mathrm{Si})$ particle shown in Fig. 5D combined with the cracked nature of the trenched area suggest the presence of hydroxide between the particle and matrix. The cracks are most likely due to dehydration caused by the low pressure of the SEM chamber. EDS analysis of the remnant of an $\mathrm{AlCuFeMn}(\mathrm{Si})$ particle indicated a decreased $\mathrm{Al}$ content of $\sim 18 \mathrm{wt} \%$, whereas the typical weight percent of $\mathrm{Al}$ in an $\mathrm{AlCuFeMn}(\mathrm{Si})$ particle was found to range from 50 to 80 wt $\%$. Similar trenching is not as obvious on the full surface exposed at $50^{\circ} \mathrm{C}$ (Fig. 5A), however, a magnified view of an IMC (Fig. 5C) reveals trenching at $50^{\circ} \mathrm{C}$, also.

Fig. 6 shows SEM images of samples immersed in $4.0 \mathrm{mM} \mathrm{NaVO}_{3}$ at $10,30,50$, and $70^{\circ} \mathrm{C}$. For samples exposed at $50^{\circ} \mathrm{C}$ and below, no obvious localized corrosion such as trenching was observed on either the noble $\mathrm{AlCuFeMn}(\mathrm{Si})$ IMCs or the active S-phase, which displayed dealloying or dissolution after 60 minutes at all temperatures in the absence of $\mathrm{NaVO}_{3}$. Slight discoloration surrounding S-phase, however, suggests the possible initiation of trenching at $50^{\circ} \mathrm{C}$ (Fig. $6 \mathrm{E}$ ). Likewise, no obvious localized corrosion was observed on the sample

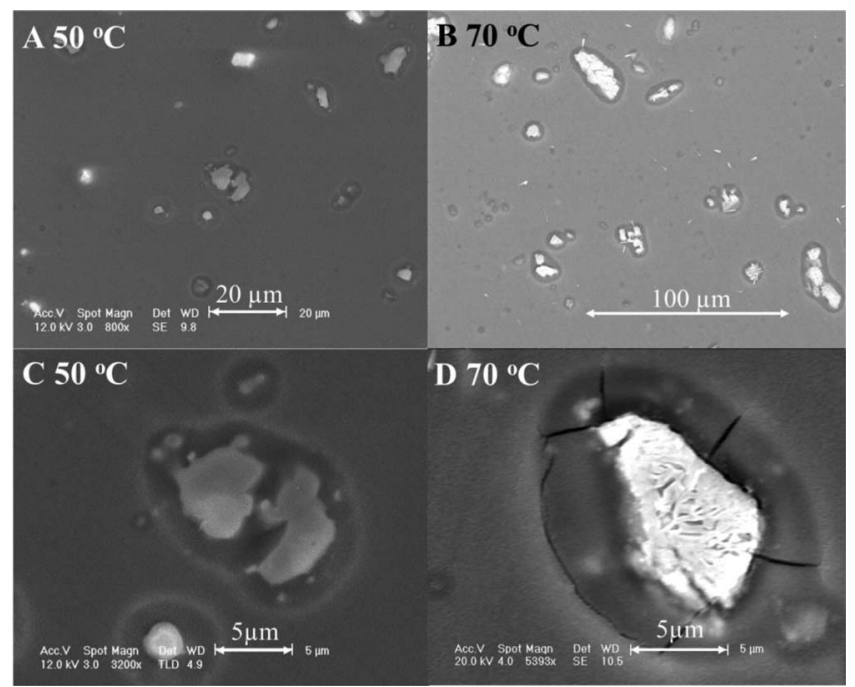

Figure 5. Corrosion morphology after exposure in DI water. (A) AA2024 at $50^{\circ} \mathrm{C}$; (B) AA2024 at $70^{\circ} \mathrm{C}$; (C) unidentified IMC on AA2024 at $50^{\circ} \mathrm{C}$; (D) $\mathrm{AlCuFeMn}(\mathrm{Si})$ particle at $70^{\circ} \mathrm{C}$.
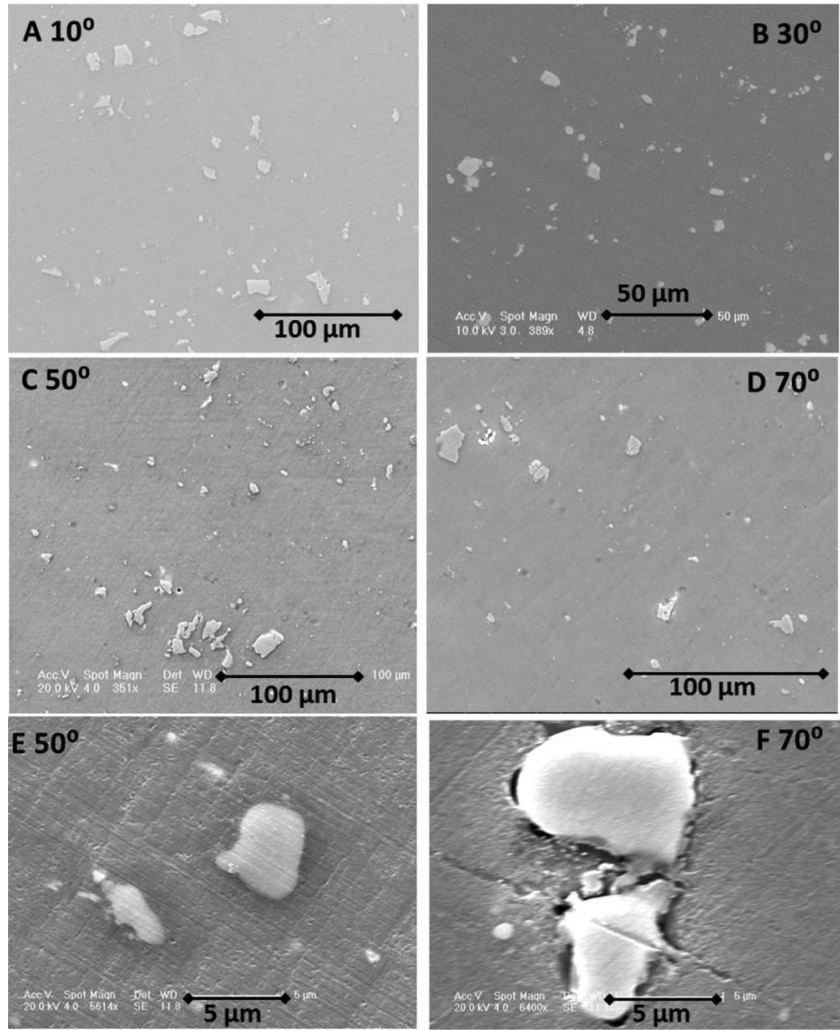

Figure 6. Corrosion morphology of AA2024-T3 after exposure in $4.0 \mathrm{mM}$ $\mathrm{NaVO}_{3}$. (A) at $10^{\circ} \mathrm{C}$; (B) at $30^{\circ} \mathrm{C}$; (C) at $50^{\circ} \mathrm{C}$; (D) at $70^{\circ} \mathrm{C}$; (E) S-phase on AA2024 at $50^{\circ} \mathrm{C}$; (F) S-phase on AA2024 at $70^{\circ} \mathrm{C}$.

exposed at $70^{\circ} \mathrm{C}$ (Fig. 6D), however, a magnified view of an S-phase particle (Fig. 6F) reveals some corrosion at the edge of the particle. EDS analysis detected no vanadium on S-phase particles exposed at temperatures of $50^{\circ} \mathrm{C}$ and lower. EDS analysis of S-phase particles exposed at $70^{\circ} \mathrm{C}$ revealed a very small peak for vanadium, while analysis of S-phase exposed at $80^{\circ} \mathrm{C}$ (Fig. 7) resulted in a strong, measureable peak for vanadium, which translated to about $1.5 \mathrm{wt} \%$. Similar to the samples exposed at $70^{\circ} \mathrm{C}$, corrosion was present at the edge of $\mathrm{S}$-phase particles, and it appeared to be more pronounced on samples exposed at $80^{\circ} \mathrm{C}$. Even at this high temperature, however, no corrosion was observed at the $\mathrm{AlCuFeMn}(\mathrm{Si})$ particles. EDS mapping over an area containing an S-phase particle exposed at $80^{\circ} \mathrm{C}$ (Fig. 7) indicates that vanadium was not uniformly distributed over the entire surface; vanadium was more concentrated on S-phase particle. Also of note is the visible color of samples exposed in aqueous vanadium at both higher temperatures. Visual inspection of samples exposed at $70^{\circ} \mathrm{C}$ showed a light yellow surface after 60 minutes of exposure which became darker after exposure to room air. A similar shade of yellow was visually observed on the samples treated at $80^{\circ} \mathrm{C}$, however, it was more intense than that noted on the samples exposed at $70^{\circ} \mathrm{C}$.

FIB analysis. - FIB was employed to study the surface film on S-phase and $\mathrm{AlCuFeMn}(\mathrm{Si})$ particles exposed at $80^{\circ} \mathrm{C}$ in $4.0 \mathrm{mM} \mathrm{NaVO}$. Cross sections of these samples are shown in Fig. 8. Trenching with a width of $\sim 800 \mathrm{~nm}$ was observed along the edges of the rounded S-phase particles (Fig. 8A). EDS analysis of the remaining S-phase in the cross-section indicated a $\mathrm{Mg}$ concentration of $7.3 \mathrm{wt} \%$ which is approximately the same as was found in uncorroded S-phase. FIB also revealed a thin dark region with a thickness of $\sim 70 \mathrm{~nm}$ surrounding the S-phase particle, most likely due to dealloying and vanadate film formation. Fig. 8B shows the FIB cross-section analysis of an $\mathrm{AlCuFeMn}(\mathrm{Si}) /$ matrix interface. No attack is observed at the interface or on the particle. 


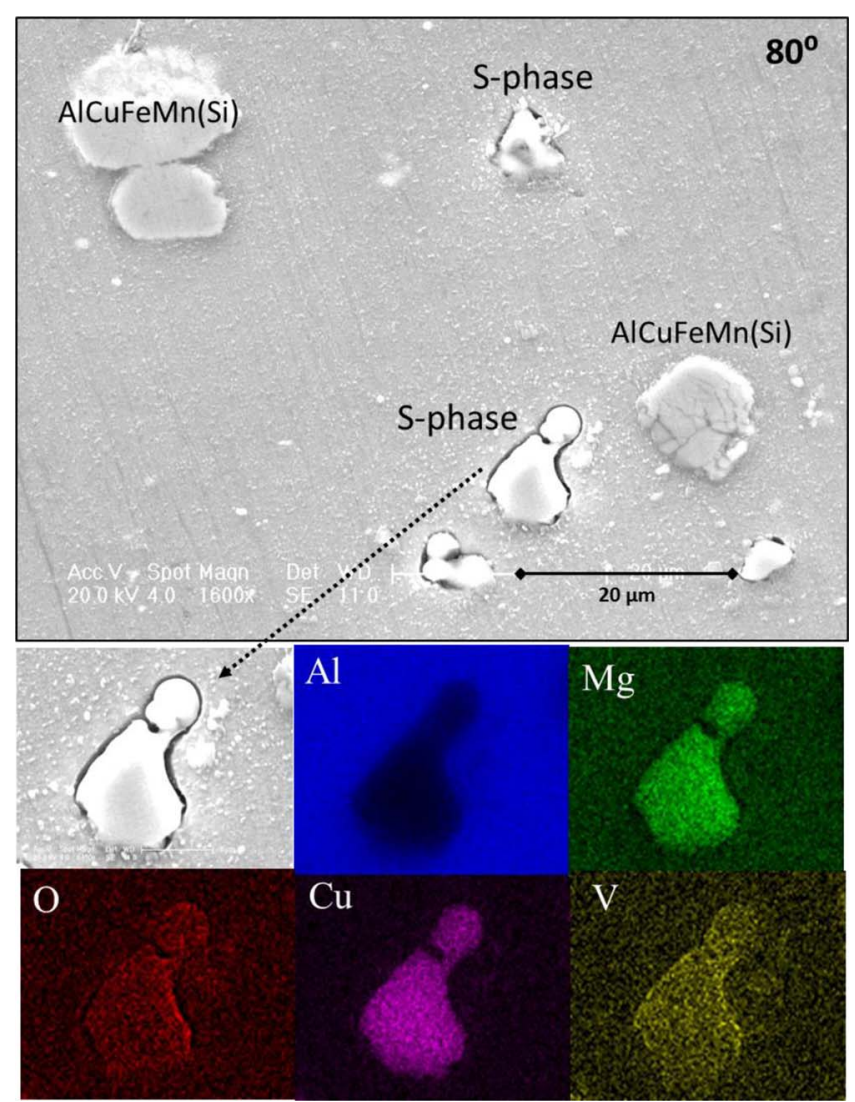

Figure 7. Corrosion morphology and EDS elemental mapping of $S$ phase particle in AA2024 after 60 min exposure in aqueous $4.0 \mathrm{mM} \mathrm{NaVO}_{3}$ at $80^{\circ} \mathrm{C}$.

EIS analysis.- EIS was conducted in a $0.1 \mathrm{M} \mathrm{NaCl}$ solution at room temperature on samples treated in $4.0 \mathrm{mM}$ vanadate at $80^{\circ} \mathrm{C}$ and samples treated in DI water at $80^{\circ} \mathrm{C}$ to study corrosion inhibition and determine whether vanadate provides any residual protection. As shown in Fig. 9, samples treated in vanadate displayed higher total impedance than those treated in DI water only. The polarization resistance increased by a factor of 4 after vanadate treatment, compared to that in DI water. Aging in dry air of vanadate-treated samples further increased $R_{p}$, which was about 7.5 times larger than the $R_{p}$ value of samples treated in DI water.

\section{Discussion}

Vanadate speciation. - Past work with vanadate as corrosion inhibitors on aluminum alloys has emphasized the importance of the speciation in solution. ${ }^{17-19,23,24}$ Although speciation is somewhat concentration dependent, $\mathrm{pH}$ is the primary determining factor with
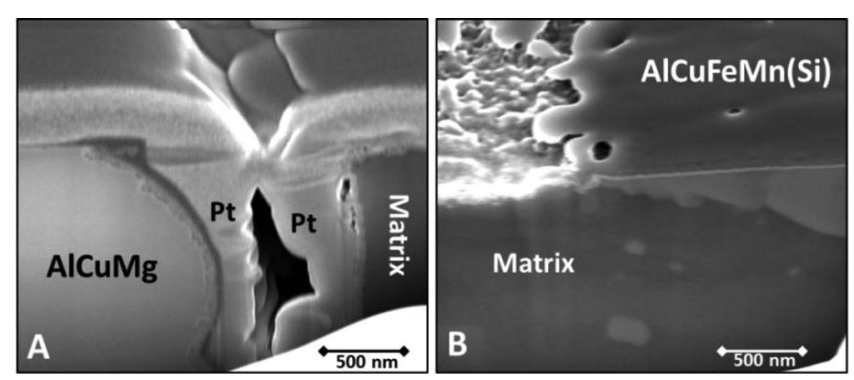

Figure 8. Secondary electron microscopy of FIB cross-sections from AA2024 samples after exposure in $4.0 \mathrm{mM} \mathrm{NaVO} 3$ at $80^{\circ} \mathrm{C}$. (A) $\mathrm{S}$ phase particle; (B) $\mathrm{AlCuFeMn}(\mathrm{Si})$ particle;.

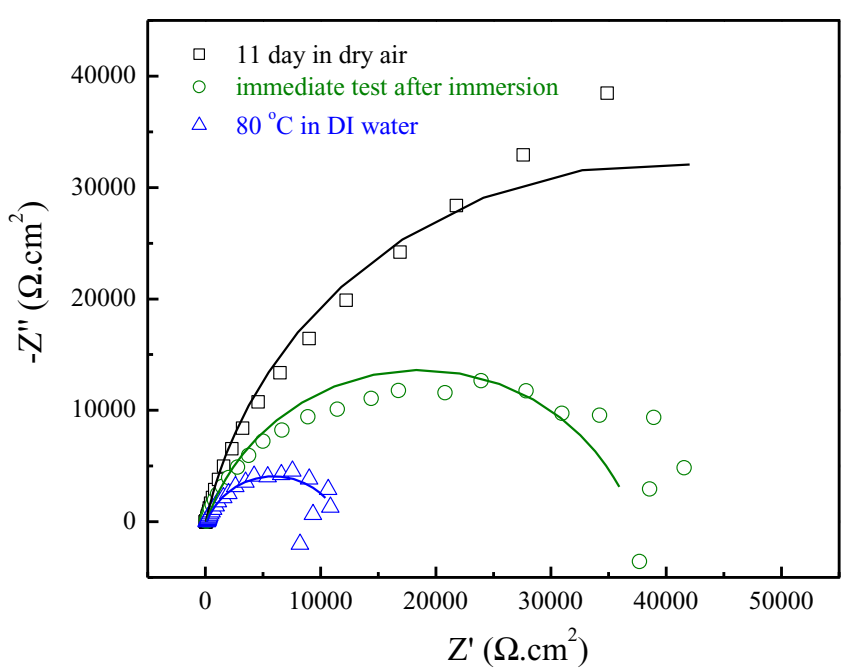

Figure 9. EIS with fitting curves in $0.1 \mathrm{M} \mathrm{NaCl}$ without any inhibitor at room temperature after $1 \mathrm{~h}$ treatment in $4 \mathrm{mM} \mathrm{NaVO}_{3}$ and DI water at $80^{\circ} \mathrm{C}$.

tetrahedrally coordinated species found at higher $\mathrm{pH}$ values and octahedrally coordinated species found at lower $\mathrm{pH}$ values at room temperature. ${ }^{17}$ In short, at ambient temperatures, exposure of aluminum alloys to aqueous solutions of tetrahedrally coordinated vanadate provides corrosion inhibition, while exposure to aqueous solutions of octahedrally coordinated vanadate does not. ${ }^{24}$ As this work adds the additional parameter of temperature control, it was first necessary to establish the speciation in the $4.0 \mathrm{mM} \mathrm{NaVO}_{3}$ solution at various temperatures. NMR analysis determined that at all temperatures used for this work the speciation of vanadate in the $\mathrm{pH}$ adjusted solutions was either $\mathrm{HVO}_{4}{ }^{2-}$ or $\mathrm{HV}_{2} \mathrm{O}_{7}{ }^{3-}\left(\mathrm{V}_{1}\right.$ or $\mathrm{V}_{2}$, respectively), both tetrahedrally coordinated compounds. $\mathrm{V}_{1}$ predominated at all temperatures and was, most likely, the only species present at temperatures $\geq 70^{\circ} \mathrm{C}$. In addition to the noted diminution and disappearance of the peak attributed to $V_{2}$ as temperature increased, thermodynamic calculations also support the greater stability of $V_{1}$ versus $V_{2}$ at higher temperatures. ${ }^{39}$ The reactions between these two vanadate species can be described by the following equation:

$$
\mathrm{H}^{+}+2 \mathrm{HVO}_{4}^{2-} \leftrightharpoons \mathrm{HV}_{2} \mathrm{O}_{7}^{3-}+\mathrm{H}_{2} \mathrm{O}
$$

The equilibrium constant can be described by the following equation

$$
\log \mathrm{K}=\log \left(\frac{C_{\mathrm{HV}_{2} \mathrm{O}_{7}{ }^{3-}}}{C_{\mathrm{H}^{+}} \times\left(C_{\mathrm{HVO}_{4}{ }^{2-}}\right)^{2}}\right)=\log \left(\frac{C_{\mathrm{HV}_{2} \mathrm{O}_{7}^{3-}}}{\left(C_{\mathrm{HVO}_{4}{ }^{2-}}\right)^{2}}\right)+\mathrm{pH}
$$

The NMR data has shown that the dominant species is $\mathrm{HVO}_{4}{ }^{2-}$, which makes up about $91 \%$ at $30^{\circ} \mathrm{C}$, and it is assumed to be $4 \mathrm{mM}$ in this calculation for simplification. Eq. 2 can be written

$$
\log \mathrm{K}=\log \left(\frac{C_{\mathrm{HV}_{2} \mathrm{O}_{7}^{3-}}}{C_{\mathrm{HVO}_{4}{ }^{2-}}}\right)+\mathrm{pH}+2.40
$$

The $\log \mathrm{K}$ values $\left(11.1,10.2,9.7\right.$ at 0,25 and $50^{\circ} \mathrm{C}$, respectively) were obtained from Larson's work, ${ }^{39}$ and the $\mathrm{pH}$ of the solution was 9.2. The calculated ratios of $\mathrm{HV}_{2} \mathrm{O}_{7}{ }^{3-}$ to $\mathrm{HVO}_{4}{ }^{2-}$ were $0.31,0.04$, and 0.013 at 0,25 and $50^{\circ} \mathrm{C}$, respectively. Therefore, thermodynamic analysis indicated that the ratio of $\mathrm{HV}_{2} \mathrm{O}_{7}{ }^{3-}$ to $\mathrm{HVO}_{4}{ }^{2-}$ should decrease with increasing temperature, in agreement with the NMR analysis which indicated that $\mathrm{HVO}_{4}{ }^{2-}$ was more stable as temperature increased.

The origin of the $2.3 \mathrm{ppm}$ shift in the $\mathrm{V}_{1}$ peak at higher temperatures is not known but the shift is mostly like due to a decrease in intermolecular interactions at higher temperatures leading to additional shielding..$^{40}$ The reappearance of the peak attributed to $V_{2}$ and 
the reversal of the $2.3 \mathrm{ppm}$ shift when the solution was returned to the original $30^{\circ} \mathrm{C}$ temperature indicate that the processes that caused the changes observed when the temperature was increased to $70^{\circ} \mathrm{C}$ were reversible. It can, therefore, be reasonably assumed that the desired tetrahedral coordination was present at each of the experimental exposure temperatures.

Temperature dependence of vanadate film formation.- Raman data established the presence of polymerized vanadate on the surfaces exposed at each temperature, albeit with little evidence of vanadate on the matrix at lower temperatures, but clear evidence of the presence of vanadate on IMCs exposed at all temperatures, including lower temperatures. Furthermore, the intensity of the band attributed to the transparent polymerized vanadate film increased with increasing exposure temperature on both the matrix (Fig. 2) and IMCs. In addition to the likelihood that higher temperatures increased the kinetics of the polymerization process, a further discussion of how temperature might have played a role in film formation is provided below in the discussion of the XPS data. Because the intensity of the scattering is theoretically linear with the amount of polymerized vanadate in the sampled volume ${ }^{41}$ it can be concluded that the film thickness or density increased with increasing exposure temperature on both the matrix and the IMCs. The Raman spectra displayed significant background (which was not removed) making quantitative measurements of the polymerized vanadate difficult. However, by integrating peak areas with imposed baselines between 600 and $1100 \mathrm{~cm}^{-1}$, it can be said with certainty that the film on the matrix exposed at $80^{\circ} \mathrm{C}$ contained over 10 times as much polymerized vanadate as the matrix exposed at $10^{\circ} \mathrm{C}$. Similar calculations from the spectra of the film formed on IMCs at different temperatures are not directly comparable since the identity of the IMCs were unknown, but it can be fairly said that the temperature effect on the intensity of the spectra of IMCs was similar to that observed on the matrix; on all analyzed IMCs the intensity of the band attributable to polymerized vanadate increased with temperature. Additionally, this band was stronger when originating from an IMC than from the matrix for each temperature, although the difference in intensity for IMC versus matrix decreased in magnitude as temperature increased. This implies that the vanadate film was more likely to form on IMCs than on the matrix at all temperatures, especially at lower temperatures.

As noted above, the EDS data also support an increased presence of vanadium with increasing temperature (no vanadium was detected on samples exposed at $50^{\circ} \mathrm{C}$ or lower, a very small amount at $70^{\circ} \mathrm{C}$ and easily measureable amounts at $80^{\circ} \mathrm{C}$ ). It is difficult to determine if the lack of evidence of vanadium from the EDS analysis of surfaces exposed at 10,30 and $50^{\circ} \mathrm{C}$ was due to a true absence of vanadium or if it resulted from limited sensitivity. It is possible that vanadate was present (and inhibiting corrosion) while the samples were immersed in the $4.0 \mathrm{mM} \mathrm{NaVO}_{3}$ at all temperatures, but that the majority of it was rinsed away before the EDS analysis was performed. Iannuzzi et al. found that vanadate provided corrosion inhibition on AA2024 while the samples were immersed in aqueous $\mathrm{NaVO}_{3}$, but that the inhibition effect disappeared when the same samples were removed, rinsed and placed in a corrosive environment without vanadate. ${ }^{18}$

The above Raman and EDS data clearly establish that, under the temperature-controlled exposure conditions herein, vanadate coverage on AA2024 increases as exposure temperature increases and that coverage on IMCs was greater than coverage on the matrix at each temperature. Enhanced coverage on IMCs and accompanying inhibition is in agreement with previous work which indicated that vanadate inhibition is more closely tied to its interactions with IMCs, notably cathodic inhibition at IMCs, than with the interactions on the matrix. ${ }^{19,23,25}$ Additionally, simple visual observation of the yellow film formed on samples exposed at 70 and $80^{\circ} \mathrm{C}$ clearly indicated the presence of a thicker film with increasing exposure temperature. It should be noted that, with aging, visual inspection also showed an increase in the intensity of the yellow color on films treated at the higher temperatures.
Oxidation states in vanadate film. - XPS data performed on samples exposed at $80^{\circ} \mathrm{C}$ and then immediately stored under two different conditions provide strong evidence that vanadium was reduced during the film formation step (Fig. 4). Samples stored in the desiccator (dry air) were exposed to oxidizing conditions whereas samples stored under argon were not. Therefore, it is reasonable to assume that whatever oxidation states for vanadium are established on the surface during exposure, those states are more likely to be present on samples stored under argon as storage time passes. Fig $3 \mathrm{~A}$ displays a shift to higher binding energy values for $\mathrm{O} 1 \mathrm{~s}(530.4$ to $532.0 \mathrm{eV})$ and a shift to lower binding energy values for $\mathrm{V} 2 \mathrm{p}_{3 / 2}(517.4$ to $516.8 \mathrm{eV})$ for samples kept in argon versus samples kept in air. Both the $\mathrm{O} 1 \mathrm{~s}$ and the $\mathrm{V} 2 \mathrm{p}_{3 / 2}$ peaks resulting from the sample kept in argon clearly display broad, unsymmetrical peaks indicating the presence of more than one species. The binding energy values at maximum intensity of the $\mathrm{O} 1 \mathrm{~s}$ $(530.4 \mathrm{eV})$ and the $\mathrm{V} 2 \mathrm{p}_{3 / 2}(517.4 \mathrm{eV})$ peaks for the sample kept in air are in agreement with binding energy values for vanadium oxides with vanadium in a $5+$ state. $^{36}$ The shoulder on the $\mathrm{O} 1 \mathrm{~s}$ peak (with a fit value of 532eV) for the sample kept in air (Fig 3C) can be attributed to oxygen in $\mathrm{Al}_{2} \mathrm{O}_{3}{ }^{37}$ Fitting of the $\mathrm{O}$ 1s peak for the sample kept in argon resulted in two peaks with binding energies similar to the two fitted $\mathrm{O} 1 \mathrm{~s}$ peaks for the sample kept in air (530.4 and $532.2 \mathrm{eV}$ ). These peaks are attributed to $\mathrm{O} 1 \mathrm{~s}$ in $\mathrm{V}_{\mathrm{x}} \mathrm{O}_{\mathrm{y}}$ and $\mathrm{Al}_{2} \mathrm{O}_{3}$, respectively. ${ }^{36,37}$ Silversmit et al. noted that the range of $\mathrm{O} 1 \mathrm{~s}$ binding energy values for vanadium oxides ranging from $\mathrm{V}^{5+}$ to $\mathrm{V}^{3+}$ is only $0.3 \mathrm{eV}^{36}$ Therefore, differences in the oxidation state of vanadium cannot easily be determined using O 1s values. However, Silversmit et al. also showed that the range of $\mathrm{V} 2 \mathrm{p}_{3 / 2}$ binding energy values for vanadium oxides ranging from $\mathrm{V}^{5+}$ to $\mathrm{V}^{3+}$ is more revealing with a difference of over one eV. As is expected, vanadium oxides with vanadium in a higher oxidation state display higher binding energy. Fitting of the $\mathrm{V} 2 \mathrm{p}_{3 / 2}$ peak originating from the sample stored in argon resulted in two distinct peaks at 517.2 and $515.8 \mathrm{eV}$, attributed to $\mathrm{V}^{5+}$ and $\mathrm{V}^{4+}$, respectively. ${ }^{36,42}$ Fitting of the $\mathrm{V} 2 \mathrm{p}_{3 / 2}$ peak for the sample stored in air also revealed two peaks at similar binding energy values, however, the peak attributable to $\mathrm{V}^{5+}$ is clearly dominant and only a small peak is attributable to $\mathrm{V}^{4+}$. These data combined with the other analyses discussed above indicate that the sample stored in argon contained vanadate with vanadium in both a $5+$ and a $4+$ state. Likewise, it suggests that the sample stored in air contained vanadate with vanadium predominantly in a 5+ state. Based on the fitting data in Fig 3, the ratio of $\mathrm{V}^{5+}$ to $\mathrm{V}^{4+}$ was 3:2 for the sample stored in argon and 22:1 for the sample stored in air. The lack of $\mathrm{V}^{4+}$ present in the sample stored in air can be attributed to oxidation of $\mathrm{V}^{4+}$ by molecular oxygen in air. Since the sample stored in argon is more likely to contain a film representative of the original exposure process, it is reasonable to assume that the adsorption/polymerization process involves and is possibly enhanced by the reduction of vanadium. Furthermore, if reduction does indeed enhance the polymerization of vanadate on a metal surface, the presence of active metals such as Mg in IMCs could provide an explanation for the enhanced presence of vanadate on IMCs. Additionally, the cathodic nature of dealloyed S-phase would also be expected to lead to enhanced reduction of vanadate. The literature appears to be absent of a discussion of the polymerization of vanadate on a metal surface, however, the presence of vanadium in both the $4+$ and $5+$ state clearly provides for electrical conductivity in the film, ${ }^{43}$ which presumably would be advantageous during the polymerization process. Furthermore, the presence of vanadium in two oxidation states during the polymerization process can perhaps be related to the redox mediation and enhanced growth rates afforded by $\mathrm{Fe}\left(\mathrm{CN}_{6}\right)^{3-}$ in the formation of the mixed chromium oxide $\left(\mathrm{Cr}^{3+} / \mathrm{Cr}^{6+}\right)$ contained in chromate conversion coatings. ${ }^{44}$

Mechanism of vanadate film formation.- Of note in the XPS data are the $\mathrm{O} 1 \mathrm{~s}$ signals originating from the two samples stored under different conditions. The ratio of oxygen from $\mathrm{Al}_{2} \mathrm{O}_{3}$ to that of oxygen in $\mathrm{V}_{\mathrm{x}} \mathrm{O}_{\mathrm{y}}$ is much larger for the sample stored in argon. A clear explanation for this occurrence does not appear obvious, however, one possibility is that as the mixed valence oxide is oxidized to a single 
valence state (sample stored in air), the structure of the film changes resulting in a thicker film, thereby hindering analytical access to the underlying $\mathrm{Al}_{2} \mathrm{O}_{3}$ film. Alternatively, perhaps the vanadate on the surface of the sample stored in argon was not yet fully polymerized but rather contained some polymerized vanadate and some monovanadate units (in both the $4+$ and $5+$ states) that did not fully cover the surface, thereby exposing more $\mathrm{Al}_{2} \mathrm{O}_{3}$ for analysis.

The latter scenario suggests that at least some (possibly most) of the actual polymerization process proceeds not in solution, but after exposure to air, during the subsequent oxidation of monovanadate in the $4+$ state. This scenario is not unlike the regeneration of a single valence $\mathrm{V}^{5+}$ oxide upon oxidation of a mixed valence $\left(\mathrm{V}^{5+} / \mathrm{V}^{4+}\right)$ oxide by gaseous $\mathrm{O}_{2}$ during the employment of vanadium oxides as catalysts for oxidative dehydrogenation reactions, which is dependent on the presence of monovanadate species. Cheng et al. described this catalytic process as involving the insertion of an $\mathrm{O}_{2}$ molecule at a $\mathrm{V}^{4+}$ site to form a cyclic $\mathrm{VO}_{2}$ peroxide, which in turn leads to oxidative dehydrogenation of a hydrocarbon such as propane. ${ }^{45} \mathrm{~A}$ similar scenario could take place between two monovanadate units (rather than a monovanadate unit and propane), leading to the polymerization of vanadate. ${ }^{45}$ Furthermore, a similar mechanism was observed by Frankel et al. on IMCs in AA2024-T3 with a molybdate inhibitor, wherein molybdate was quickly reduced at the surface of IMCs but was subsequently oxidized to protective $\mathrm{Mo}^{6+}$ oxide layer. ${ }^{46}$

Although this scenario is speculative at this point, in addition to similar reactions in vanadate catalysts, this work provides experimental and theoretical evidence to support the occurrence of a similar process to the reactions observed in vanadate catalyst noted above, albeit at the surface of metal electrode exposed to aqueous vanadate rather than at catalytic vanadate surface. In considering this scenario, it is important to distinguish between two types of $\mathrm{O}_{2}$ reduction. First, there is the typical ORR occurring at the metal electrode surface at open circuit potential (OCP) in an aerated solution, originating from the oxidation of the metal surface (and possibly some $\mathrm{V}^{4+}$ contained in adsorbed vanadate). Second, there is the reduction of $\mathrm{O}_{2}$ occurring on a dry metal electrode previously exposed to vanadate, in which case the source of electrons would be the oxidation of $\mathrm{V}^{4+}$. The second scenario clearly cannot occur without the presence of $\mathrm{V}^{4+}$, which requires the reduction of $\mathrm{V}^{5+}$ at the electrode during exposure in the aqueous solution. As supported by the above XPS data and previously established by other researchers, vanadate is a moderately strong oxidizing agent that is reduced on metal surfaces under conditions similar to these experimental conditions. ${ }^{18,47}$ The reversible potential of vanadate under the condition in this work is about $-0.15 \mathrm{~V}_{\mathrm{SCE}},{ }^{48}$ which is higher than that of $\mathrm{Mg}$ and $\mathrm{Al}$ assuming their ions concentration is $1 \mu \mathrm{M}$ in solution. The reduction of vanadate on a metal electrode in aerated aqueous solution will be in competition with the reduction of dissolved $\mathrm{O}_{2}$ (the ORR). Fig. 10 is a plot of the limiting current that can be expected from the ORR in DI water calculated based on the temperature dependence of the diffusivity of dissolved $\mathrm{O}_{2}$ (increases with temperature), ${ }^{49}$ the concentration of dissolved $\mathrm{O}_{2}$ (decreases with temperature) ${ }^{50}$ and diffusion layer thickness (decreases with temperature).$^{51}$ As can be seen, this value reaches a maximum at around $55^{\circ} \mathrm{C}$ and then drops sharply with increasing temperature. In other words, the ORR reaction at a sample of AA2024 in aqueous $\mathrm{NaVO}_{3}$ at $80^{\circ} \mathrm{C}$ is far less likely to compete with the reduction of vanadate, whereas at $50^{\circ} \mathrm{C}$ the ORR is likely to be in strong competition with the reduction of vanadate. This, in turn, could lead to enhanced coverage of $\mathrm{V}^{4+}$ on surfaces exposed at higher temperatures. The subsequent oxidation of these $\mathrm{V}^{4+}$ units (by either dissolved $\mathrm{O}_{2}$ during the exposure process or by gaseous $\mathrm{O}_{2}$ upon exposure to air) could then lead to enhanced polymerization via the path described above. This speculative scenario would explain the higher ratio of $\mathrm{Al}_{2} \mathrm{O}_{3}$ to $\mathrm{V}_{\mathrm{x}} \mathrm{O}_{\mathrm{y}}$ determined by XPS analysis found on the sample stored in argon after exposure at $80^{\circ} \mathrm{C}$ as the monovanadate units would be less likely to cover the underlying $\mathrm{Al}_{2} \mathrm{O}_{3}$ on the matrix. Since the limiting current for the ORR reaches its maximum at $55^{\circ} \mathrm{C}$, it would be expected to compete with the reduction of vanadate and thereby impede the formation of $\mathrm{V}^{4+}$ oxides and the subsequent polymerization of vanadate.

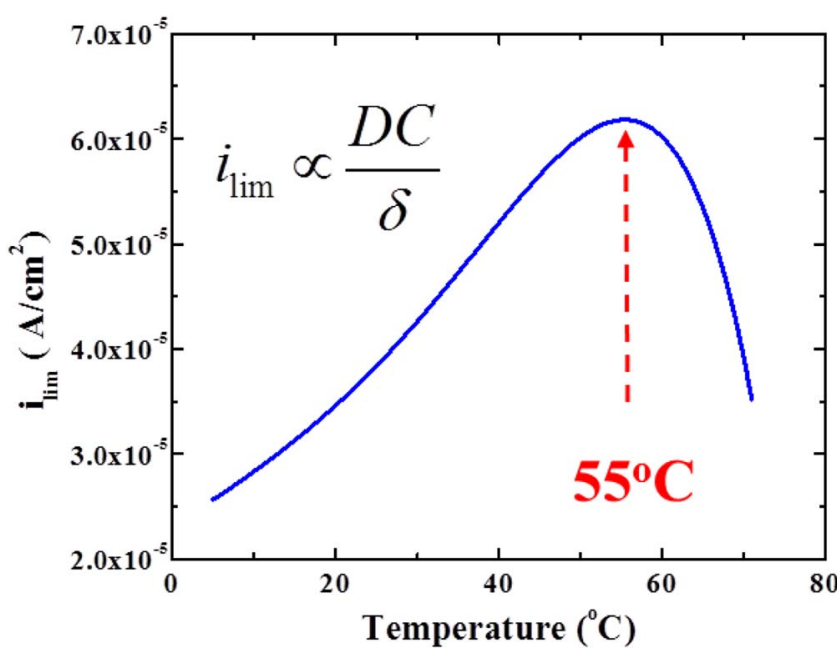

Figure 10. Limiting current density of the ORR in DI water as a function of temperature.

Iannuzzi found support for competition between the ORR and the reduction of vanadate on both AA2024 and $\mathrm{Cu}$ surfaces in aqueous vanadate solutions. ${ }^{18}$ All of this is in agreement with the reproducible anomalous low coverage of polymerized vanadate seen on samples exposed at $50^{\circ} \mathrm{C}$, as determined with Raman analysis. Lastly, this scenario would explain the increase in visual yellow intensity observed with aging on the samples treated at 70 and $80^{\circ} \mathrm{C}$ and the enhanced polymerization found in IMCs.

Empirical evidence of corrosion inhibition. - The EDS/SEM data provide strong evidence that not only does vanadate provide corrosion inhibition but that an increase in exposure temperature in the presence of $\mathrm{NaVO}_{3}$ leads to increased corrosion inhibition. This is evidenced by the corrosion protection it provided at the high temperatures, which lead to significantly increased corrosion activity in the absence of $\mathrm{NaVO}_{3}$. Not surprisingly, the EDS results of samples exposed in DI water (without the presence of vanadate) demonstrate that localized corrosion is enhanced as temperature increases (Fig. 5). SEM images of samples exposed in DI water at 10 and $30^{\circ} \mathrm{C}$ (not shown) also presented evidence of significant attack at IMCs, albeit less than that on samples exposed at 50 and $70^{\circ} \mathrm{C}$. With the addition of $\mathrm{NaVO}_{3}$ during exposure, less attack was observed at the IMCs at each temperature. This is demonstrated by a comparison of Fig. 5B and Fig. $6 \mathrm{D}$ (without and with $\mathrm{NaVO}_{3}$, respectively) which shows that localized corrosion was inhibited by the addition of vanadate at $70^{\circ} \mathrm{C}$. At $70^{\circ} \mathrm{C}$, trenching was observed, but it was not as severe and was present only at the very edge of an S-phase particle when vanadate was present in the exposure solution (Fig. 6F). The results observed on the sample exposed at $80^{\circ} \mathrm{C}$ (Fig. 7) provide further evidence of vanadate's ability to inhibit corrosion at high temperatures; compare the severe trenching at a $\mathrm{AlCuFeMn}(\mathrm{Si})$ particle exposed in $\mathrm{DI}$ water at $70^{\circ} \mathrm{C}$ (Fig. 5D) to the virtually pristine $\mathrm{AlCuFeMn}(\mathrm{Si})$ particles shown in Fig. 7 (exposure in $\mathrm{NaVO}_{3}$ at $80^{\circ} \mathrm{C}$ ). The enhanced vanadium present on S-phase particles (Fig. 7) suggests that the inhibition exhibited at high temperatures originates from a mechanism similar to that discussed in previous work at ambient temperatures, notably an inhibition of the ORR at copper-rich IMCs. ${ }^{18,25}$ Specifically, the oxide on $\mathrm{Cu}$-rich IMCs has been found to support the formation of polymerized vanadate at a level greater than that of the matrix. ${ }^{19}$ Similarly, enhanced amounts of vanadium present on S-phase particles might be attributed to the reduction of vanadate by the active $\mathrm{Mg}$ or $\mathrm{Al}$ in S-phase resulting in reductive adsorption, producing a mixed valence vanadate oxide $\left(\mathrm{V}^{4+} / \mathrm{V}^{5+}\right)$. A similar process was observed by Iannuzzi and Nazarov, wherein reduction of vanadate by zinc resulted in a vanadate-based film. ${ }^{16}$ Frankel et al. found that vanadate 


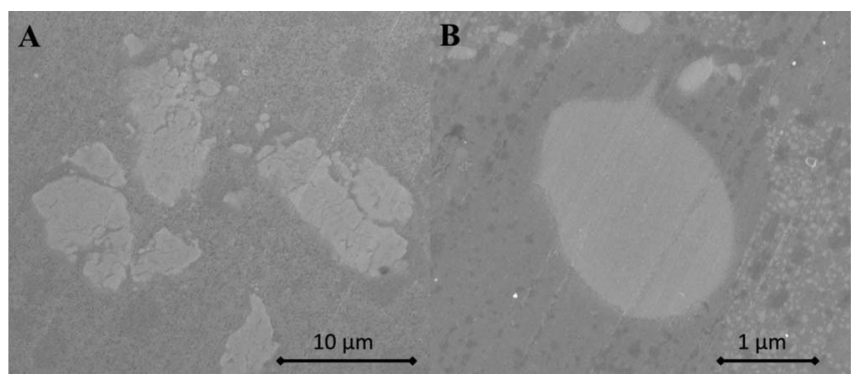

Figure 11. Corrosion morphology of IMCs (A, AlCuMnFe particles; $\mathrm{B}, \mathrm{S}$ phase particle) after 1 hour exposure in $0.1 \mathrm{M} \mathrm{NaCl}+1 \mathrm{mM} \mathrm{CrO}_{4}{ }^{2-}$ at $70^{\circ} \mathrm{C}$

provided very effective corrosion inhibition on $S$ phase particles even when the protective layer was disturbed with AFM scratching. ${ }^{22}$

The FIB data provide additional insight into vanadate interactions with IMCs. Although the FIB image in Fig. $8 \mathrm{~A}\left(80^{\circ} \mathrm{C}\right.$ exposure) shows clear trenching surround the S-phase particle, it is not clear whether this arose from dissolution of the IMC or from dissolution of the matrix surrounding the IMC (or a combination of both). Because EDS elemental analysis on the cross-section of $\mathrm{S}$ phase, however, indicated that the percentage of $\mathrm{Mg}$ in the corroded $\mathrm{S}$ phase was approximately the same as that in uncorroded particle, dissolution of the matrix is the most likely origin of the trenched volume. This suggests that the exposure in $\mathrm{NaVO}_{3}$ prevented or inhibited the dissolution of $\mathrm{Mg}$ from the IMC in addition to the likelihood that it inhibits the ORR on the S-phase surface. The lack of attack in the area surrounding the $\mathrm{AlCuFeMn}(\mathrm{Si})$ particle after exposure at $80^{\circ} \mathrm{C}$ is further evidence of the inhibiting effect.

The EIS data of samples treated at $80^{\circ} \mathrm{C}$ (Fig. 9) demonstrate evidence that treatment at high temperatures provides considerable corrosion inhibition. This is particularly noteworthy when one considers that the only source of vanadate was the vanadate film present on the treated sample which had been thoroughly rinsed before placement in the $\mathrm{NaCl}$ solution for EIS analysis. Previous work indicated that although vanadate provided corrosion inhibition on AA2024 surfaces when the surfaces were analyzed in aqueous vanadate solutions at room temperature, the residual vanadate films on these surfaces (present after rinsing or rinsing combined with aging) did not provide corrosion inhibition in subsequent polarization experiments performed in aqueous $\mathrm{NaCl}$ without the presence of dissolved $\mathrm{NaVO}_{3} .{ }^{18,19}$ If the reductive adsorption of vanadate is instrumental in providing enhanced corrosion inhibition, as discussed above, the residual inhibition displayed by the samples treated at $80^{\circ} \mathrm{C}$ can be viewed as evidence that the higher temperatures lead to more reductive adsorption. Furthermore, the increased impedance observed on the aged samples is in agreement with increased polymerization arising from the insertion of oxygen via the oxidation of $\mathrm{V}^{4+}$ vanadate units.

The corrosion morphology and EIS measurements clearly demonstrate that vanadate provides good inhibition of localized corrosion. The inhibition mechanism at high temperature appears to be closely related to the polymeric vanadate film, which can be promoted by the chemical reduction of vanadate by $\mathrm{Al}$ or $\mathrm{Mg}$, providing residual protection. This mechanism is similar to that of chromate on aluminum alloys, which is reduced by $\mathrm{Al}$ or $\mathrm{Mg}$ and forms a protective compact layer on the surface. However, the inhibition efficiency of vanadate at high temperatures is not as rigorous as that provided by chromate, especially for the active $S$ phase particles. Fig. 11 shows the corrosion morphology of $\mathrm{AlCuMnFe}$ and $\mathrm{S}$ phase particles after 1 hour exposure in $0.1 \mathrm{M} \mathrm{NaCl}$ with $1 \mathrm{mM} \mathrm{K}_{2} \mathrm{CrO}_{4}$ at $70^{\circ} \mathrm{C}$. No localized corrosion is observed at either type particle. Compared to the corrosion morphology associated with $\mathrm{S}$ phase and AlCuMnFe particles in vanadate solution under the same conditions, inhibition of vanadate on $\mathrm{S}$ phase particles is not as good as chromate, while it is comparable for Al$\mathrm{CuMnFe}$ particles. The above results demonstrate that vanadate can serve as a strong inhibitor when applied and tested under moderately high temperature conditions. These preliminary results can serve as a strong foundation for use of vanadate for moderately high temperature corrosion inhibition. However, due to the extensive successful use of chromate as a corrosion inhibitor over many decades and under a wide variety of conditions, ${ }^{52-54}$ the challenge of replacing chromate under high temperature conditions will require a considerable extension of this work.

\section{Conclusions}

1. Exposure of AA2024 to aqueous tetrahedrally coordinated $\mathrm{NaVO}_{3}$ results in the formation of a vanadate film on the surface of the alloy. The quantity and location of film formation is dependent on the temperature of the exposure solution. At low temperatures $\left(10,30\right.$ and $\left.50^{\circ} \mathrm{C}\right)$, the film is found primarily on IMCs with little or no presence on the matrix. At high temperatures $\left(70\right.$ and $\left.80^{\circ} \mathrm{C}\right)$ the film is found on both the matrix and IMCs. An increase in the temperature of the exposure solution leads to an increase in the amount of film formed on both IMCs and the matrix. At all exposure temperatures, vanadate film formation was enhanced at IMCs versus the matrix. This effect was more pronounced at low temperatures.

2. Analysis of the film formed on both the IMCs and the matrix (when solution exposure was followed by exposure to air) showed that it consists primarily of polymerized vanadate with the majority of vanadium in the $5+$ state. Analysis of the film formed after solution exposure but with minimal subsequent exposure to air suggested the presence of a non-continuous film wherein the ratio of $\mathrm{V}^{5+}: \mathrm{V}^{4+}$ was $3: 2$.

3. It is proposed that polymerization of vanadate oxide can proceed through the insertion and reduction of $\mathrm{O}_{2}$ at $\mathrm{V}^{4+}$ centers (both in solution and in air during aging). Therefore, the reduction of $\mathrm{V}^{5+}$ on the metal surface during exposure enhances subsequent polymerization. Assuming that the ORR and reduction of $\mathrm{V}^{5+}$ occur competitively at the metal surface during exposure, the theoretical temperature-dependent limiting current for the ORR suggests that reduction of $\mathrm{V}^{5+}$ to $\mathrm{V}^{4+}$ will be maximized at higher temperatures. This temperature effect is proposed as a reason for enhanced film coverage at higher temperatures (low ORR current) and exceptionally low coverage at $50^{\circ} \mathrm{C}$, the temperature at which the ORR is maximized.

4. In addition to enhanced reductive adsorption of vanadium due to high temperatures, it is expected that high temperatures enhance the kinetics of film formation and/or surface adsorption.

5. In addition to providing corrosion inhibition at IMCs exposed at low temperatures, vanadate provides corrosion inhibition at IMCs exposed at high temperatures, where attack at IMCs is especially extensive without the presence of an inhibitor. At all exposure temperatures, in the presence of aqueous $\mathrm{NaVO}_{3}$, attack at $\mathrm{AlCuFeMn}(\mathrm{Si})$ particles was essentially non-existent and the dealloying of S-phase was greatly reduced.

\section{Acknowledgments}

Research was sponsored by the Army Research Laboratory and was accomplished under Cooperative Agreement Number W911NF14-2-0004. The views and conclusions contained in this document are those of the authors and should not be interpreted as representing the official policies, either expressed or implied, of the Army Research Laboratory or the U.S. Government. The U.S. Government is authorized to reproduce and distribute reprints for Government purposes notwithstanding any copyright notation herein. Purchase of the Raman microprobe was supported by the National Science Foundation under Grant No. 0639163.

\section{References}

1. L. F. Mondolfo, Aluminum alloys: structure and properties, Butterworths, London, Boston, (1976).

2. J. E. Hatch, Aluminum: properties and physical metallurgy, American Society for Metals, Metals Park, Ohio, (1984). 
3. G. O. Ilevbare, O. Schneider, R. G. Kelly, and J. R. Scully, J. Electrochem. Soc., 151, B453 (2004).

4. R. G. Buchheit, R. P. Grant, P. F. Hlava, B. Mckenzie, and G. L. Zender, J. Electrochem. Soc., 144, 2621 (1997).

5. A. Boag, Corros. Sci., 51, 1565 (2009).

6. N. Birbilis and R. G. Buchheit, J. Electrochem. Soc., 152, B140 (2005).

7. N. Birbilis and R. G. Buchheit, J. Electrochem. Soc., 155, C117 (2008).

8. A. Boag, A. E. Hughes, A. M. Glenn, T. H. Muster, and D. McCulloch, Corros. Sci., 53, 17 (2011)

9. G. S. Chen, M. Gao, and R. P. Wei, Corrosion, 52, 8 (1996).

10. N. Birbilis, M. K. Cavanaugh, and R. G. Buchheit, Corros. Sci., 48, 4202 (2006).

11. R. G. Buchheit, JOM, 53, 29 (2001)

12. M. B. Vukmirovic, N. Dimitrov, and K. Sieradzki, J. Electrochem. Soc., 149, B428 (2002).

13. R. G. Buchheit, M. A. Martinez, and L. P. Montes, J. Electrochem. Soc., 147, 119 (2000).

14. R. L. Cook and S. R. Taylor, Corrosion, 56, 321 (2000).

15. C. S. Lin, H. C. Lin, K. M. Lin, and W. C. Lai, Corros. Sci., 48, 93 (2006).

16. A. Nazarov, D. Thierry, T. Prosek, and N. Le Bozec, J. Electrochem. Soc., 152, B220 (2005).

17. K. D. Ralston, S. Chrisanti, T. L. Young, and R. G. Buchheit, J. Electrochem. Soc., 155, C350 (2008).

18. M. Iannuzzi and G. S. Frankel, Corros. Sci., 49, 2371 (2007).

19. B. L. Hurley, S. Qiu, and R. G. Buchheit, J. Electrochem. Soc., 158, C125 (2011).

20. B. L. Hurley, K. D. Ralston, and R. G. Buchheit, J. Electrochem. Soc., 161, C471 (2014).

21. V. M. Iannuzzi and G. Frankel, ECS Trans., 3, 127 (2007).

22. M. Iannuzzi and G. S. Frankel, Corrosion, 63, 672 (2007).

23. M. Iannuzzi, J. Kovac, and G. S. Frankel, Electrochim. Acta, 52, 4032 (2007).

24. M. Iannuzzi, T. Young, and G. S. Frankel, J. Electrochem. Soc., 153, B533 (2006).

25. K. D. Ralston, T. L. Young, and R. G. Buchheit, J. Electrochem. Soc., 156, C135 (2009).

26. B. D. Chambers, S. R. Taylor, and M. W. Kendig, Corrosion, 61, 480 (2005).

27. A. S. Hamdy, I. Doench, H. Mohwald, and H. Möhwald, Thin Solid Films, 520, 1668 (2011).

28. H. Guan and R. G. Buchheit, Corrosion, 60, 284 (2004).
29. P. Wang, X. Dong, and D. W. Schaefer, Corros. Sci., 52, 943 (2010).

30. R. G. Buchheit, H. Guan, S. Mahajanam, and F. Wong, Prog. Org. Coatings, 47, 174 (2003).

31. K. D. Ralston and R. G. Buchheit, ECS Electrochem. Lett., 2, C35 (2013).

32. F. W. Eppensteiner and M. R. Jenkins, Met. Finish., 99, 494 (2001).

33. G. Lu, E. T. Ada, and G. Zangari, Electrochim. Acta, 49, 1461 (2004).

34. M. K. Cavanaugh, J.-C. Li, N. Birbilis, and R. G. Buchheit, J. Electrochem. Soc., 161, C535 (2014).

35. A. J. Bard and L. R. Faulkner, Electrochemical methods: fundamentals and applications, 2nd ed., John Wiley, New York, (2001).

36. G. Silversmit, D. Depla, H. Poelman, G. B. Marin, and R. De Gryse, J. Electron Spectros. Relat. Phenomena, 135, 167 (2004).

37. A. K. Dua, V. C. George, and R. P. Agarwala, Thin Solid Films, 165, 163 (1988).

38. Debbie C Crans and Alan S Tracey, Vanadium Compounds A. S. Tracey and D. C. Crans, Editors, American Chemical Society, Washington, DC, (1998), p. 2.

39. J. W. Larson, J. Chem. Eng. Data, 40, 1276 (1995).

40. C. J. Jameson, Bull. Magn. Reson., 3, 3 (1981).

41. R. McCreery, Raman spectroscopy for chemical analysis J. D. Winefordner, Editor, John Wiley \& Sons, New York, (2000), p. 420.

42. R. J. Colton, A. M. Guzman, and J. W. Rabalais, J. Appl. Phys., 49, 409 (1978).

43. J. Livage, Solid State Ionics, 86, 935 (1996).

44. L. Xia and R. L. McCreery, J. Electrochem. Soc., 146, 3696 (1999)

45. M.-J. Cheng, K. Chenoweth, J. Oxgaard, A. VanDuin, and W. A. Goddard, J. Phys. Chem. C, 111, 5115 (2007)

46. O. Lopez-Garrity and G. S. Frankel, J. Electrochem. Soc., 161, C95 (2013).

47. A. F. White and M. L. Peterson, Geochim. Cosmochim. Acta, 60, 3799 (1996).

48. M. Pourbaix, Atlas of electrochemical equilibria in aqueous solutions, 2d English., National Association of Corrosion Engineers, Houston, Tex., (1974).

49. P. Han and D. M. Bartels, J. Phys. Chem., 100, 5597 (1996).

50. G. A. Truesdale and A. L. Downing, Nature, 173, 1236 (1954)

51. V. V. Gerasimov and I. L. Rozenfeld, Bull. Acad. Sci. USSR Div. Chem. Sci., 5, 797 (1956).

52. E. Blasco-Tamarit, A. Igual-Muñoz, J. G. Antón, and D. García-García, Corros. Sci., 50, 1848 (2008)

53. M. A. Heine and M. J. Pryor, J. Electrochem. Soc., 114, 1001 (1967).

54. M. W. Kendig, A. J. Davenport, and H. S. Isaacs, Corros. Sci., 34, 41 (1993). 